\title{
Socio-ecological vulnerability and resilience of mountain communities residing in capital-constrained environments
}

\author{
Shashidhar Kumar Jha ${ }^{1}$ (D) A. K. Negi ${ }^{1}$ Juha M. Alatalo ${ }^{3} \cdot$ R. S. Negi ${ }^{2}$
}

Received: 29 May 2020 / Accepted: 16 September 2021 / Published online: 1 November 2021 (c) The Author(s), under exclusive licence to Springer Nature B.V. 2021

\begin{abstract}
The study evaluated perceived reactions and counter-actions of Himalayan communities to climate change. The evaluation was conducted through identification and characterization of 62 socio-environment-specific indicators in three altitude zones $(<1200 \mathrm{~m}$ asl (zone A), 1200-1800 m asl (zone B), and >1800 m asl (zone C)) in Pauri district, Uttarakhand, India, using a bottom-up, indicator-based approach. Indicators with higher significance for the local economy, livelihoods, or conservation were selected and assimilated into dimensions of vulnerability and resilience. Finally, these were integrated into a sustainable livelihood framework in an approach intended to calculate vulnerability and resilience jointly. The results indicated that the vulnerability and resilience of the mountain communities studied varied widely along the altitude gradient, due to variations in socioeconomic profile, livelihood requirements, resource availability, accessibility, and utilization pattern, and climate risk. The overall values for vulnerability (exposure + sensitivity-adaptive capacity) and resilience (exposure + sensitivity-restorative capacity) were, respectively, 0.34 and 0.28 in zone A, 0.54 and 0.37 in zone B, and 0.65 and 0.59 in zone C. There was a significant difference in contribution of indicators to vulnerability and resilience along the altitudinal gradient was recorded. Strategies for dealing with site-specific vulnerability are required and should address bottlenecks in accessibility and availability of food, water, and healthcare; sustainable utilization of forest resources; educational attainment and skill enhancement; and migration. These results extend current knowledge among the research community and policymakers on socio-ecological changes affecting mountain communities. To reduce the policy level gap between bottom-up and top-down approaches, we suggest precautionary and ongoing site-specific traditional practices and modern adaptation practices, leading to effective and efficient handling of local issues in the context of climate change.
\end{abstract}

Keywords Himalaya $\cdot$ Resilience index $\cdot$ Adaptive capacity $\cdot$ Socio-ecological system

Shashidhar Kumar Jha

shashidharkj@gmail.com

1 Department of Forestry and Natural Resources, Hemvati Nandan Garhwal (A Central) University, Uttarakhand, Srinagar, India

2 Department of Rural Technology, Hemvati Nandan Garhwal (A Central) University, Uttarakhand, Srinagar, India

3 Environmental Science Center, Qatar University, Doha, Qatar 


\section{Introduction}

Mountain ecosystems are a rich natural repository that provides many goods and services to mankind. They are a key source of water, energy, minerals, and forests products and play a crucial role in economic development, environmental safety, and ecological protection (Macchi et al. 2011). The high mountains are regions of great diversity (in terms of flora, fauna, and culture), which gives advantages for socio-ecological development. The geo-ecological conditions, i.e., landscape and climate, provide a window of opportunity for sustainable livelihoods. However, remoteness, inaccessible terrain, and marginality restrict the utilization of these potential resources. The process of development in mountainous regions is already slow and further inhibited by regional specificities (Jodha 1992). These constraints separate mountain ecosystems from mainstream development (Ariza et al. 2013), and such regions are unable to keep pace with progress elsewhere. Thus, mountains are sites of grinding poverty, marginality, and inequalities. The insecure livelihood, with few opportunities to work in a balanced ecosystem, continuously deteriorates humanmountain or socio-ecological interactions (Jha et al. 2018).

The Himalayas are among the world's most fragile, susceptible, and vulnerable mountains (Pandey and Jha 2011) and are intensely affected by climate change. The impact of climate change in the Himalayan region is multidimensional (Green et al. 2009) and is likely to have wider impacts on socioeconomic (Beniston, 2003) and ecological systems (Upgupta et al. 2015). Climate change, along with harsh living conditions, marginal locations, economic disparities, and weak decision-making capability, further increases the vulnerability (Nogues-Bravo et al. 2007) of communities residing in food-insecure and water-scarce mountainous regions (Kohler and Maselli 2009). The vulnerability of these communities is increased by limited access to resources and simultaneous pressure for economic development (mining, hydro-electric dams, hotels, deforestation, etc.). This weakens the ecosystem balance and acts as a co-factor to climate change in increasing the vulnerability of mountain communities (Kohler and Maselli 2009).

An impact on one component of an ecosystem also alters the stability of associated or interdependent components (Moser 1998; Obrist 2006). The vulnerability of socio-ecological system is often an outcome of natural disasters and of over-exploitation or unsustainable utilization of resources (Jha et al. 2017). Overall, disturbances in socio-ecological systems lead to poverty, marginalization, and exclusion (Barnett 2001) and also alter flow of services (Parmesan and Yohe 2003). An ability to cope with disturbances is considered to be a critical element in continuous evolution of resource use patterns and human settlements (Jha et al. 2017). However, additional anthropogenic pressure on resources upsets the natural balance (FAO 2011) and creates vulnerability in the socio-ecological system (Pandey and Jha 2011).

Vulnerability is location- and context-specific (Handmer et al. 1999) and is defined differently in different contexts. The simplest definition in the literature arises from the Latin origin, vulnerare, which means "to wound," so vulnerability is basically defined as "the capacity to be wounded" (Kates et al. 1985). In a social perspective, vulnerability is defined as "the degree to which a system is susceptible to injury, damage or harm" (IPCC 2001). Vulnerability in the present study was represented by a suite of human-ecological factors reflecting exposure (climate stress on households), sensitivity (degree to which a system is exposed), and adaptive capacity (internal or external capacity to cope). In this perspective, effective baseline assessment of a socio-ecological system deals with its capacity to restore or recover from non-structural change, a dimension not included in vulnerability 
assessments. Thus, in the present study, resilience, i.e., the capacity of a complex system to remain within a regime in the face of external perturbations and/or internal change (Holling 1973), was considered together with vulnerability.

Resilience has been used previously in ecology, e.g., to study the population ecology of plants and animals and in ecosystem management. Since the 1980s, the concept has increasingly been used to study how humans affect the resilience of ecosystems (Janssen and Ostrom 2006). According to Carpenter et al. (2001), "resilience reflects the degree to which a complex adaptive system is capable of self-organization." Resilience measures the ability of a system to absorb perturbation and its regenerative ability for continual delivery of services to consumers (Adger et al. 2005). Resilience is the ability of a system that keeps it in a stable state, instead of suffering non-linear fluctuations in social and ecological parameters (Janssen and Ostrom 2006). In general terms, it is an attempt to control changes in a system assumed to be stable, or the robustness of a socio-ecological system to uncertainty (Adger, 2000).

The conceptual links between adaptive capacity, vulnerability, and resilience are explained by Gallopin (2006) using socio-ecological systems. These domains differ in conceptual structure, and resilience is only weakly correlated with vulnerability (Janssen et al. 2006). Therefore, attempts have been made to assess vulnerability together with resilience of socio-ecological systems and establish the relationships between them. Vulnerability consists of exposure, sensitivity, and adaptive capacity (IPCC 2001). Exposure is the potential impact of climate change (Ebi et al. 2006) and is almost equal for a system and for vulnerability or resilience. It is the beginning, start-point, or initial stage of vulnerability. The impact of exposure relies on its scale, system sensitivity, and adaptive capacity. Sensitivity is "degree of exposure" (IPCC 2001), and it varies at spatial and temporal scale because it is an internal phenomenon (Pandey and Jha 2011). Sensitivity is also a nonseparable part of resilience and it is an important dimension used for assessment of resilience. A sensitive system has lower capacity to restore itself, i.e., weaker resilience. For example, torrential rainfall may increase the sensitivity of soil to erosion and also reduce its capacity to restore itself to its previous state. Adaptive capacity is the capability of the system to protect socio-ecological systems from changes or perturbation (Pandey and Jha 2011). It involves improvement or adjustment in systems, even without change. Adaptive capacity can also include reactions of the system that modify its sensitivity to perturbation (Gallopin 2006). However, the resilience of a system is not completely explained by these dimensions of vulnerability (i.e., exposure, sensitivity, and adaptive capacity). Therefore, in the present study, resilience was considered to be a function of exposure, sensitivity, and restorative capacity. Restorative capacity is set of indicators that explain the capacity to absorb changes, restore system components, and bring the system back to its previous condition.

This approach enables use of combined and individual scores of dimensions at spatial scale, which helps to identify suitable options or strategies that would be feasible and realistic at micro level (Smit and Wandel 2006). The overall aim of the present study was to perform an integrated assessment of the vulnerability and resilience of socio-ecological systems along an altitude gradient in the Indian Himalayas region, using a bottom-up, indicator-based approach. Specific objectives were to identify (i) community requirements that must be emphasized at micro level and prioritized at macro level to promote policy or program development and (ii) indicators that reflect or condense vulnerability and can thus be used in an appropriate mechanism for strengthening resilience through holistic and longterm sustainable management of resources. Improvement of adaptation approaches is pertinent in the Himalayas region for vulnerability reduction and reinforcement of resilience. 
Identification of community requirements and indicators would also be helpful in identification and prioritization of sectors and policy formulation, together with implementation of a suitable regional adaptation program. Thus, an additional aim in this study was to provide recommendations for setting priorities for action, while also helping to develop a robust, integrated model approach to increasing resilience to climate risks at national and local levels.

\section{Study site}

The study was conducted in Pauri district, Uttarakhand, India. The district $\left(29^{\circ} 20^{\prime}-30^{\circ}\right.$ $15^{\prime} \mathrm{N} ; 78^{\circ} 10^{\prime}-79^{\circ} 20^{\prime} \mathrm{E}$ ) is at a mean elevation of $1800 \mathrm{~m}$ above sea level (asl) (range 210-7817 m asl) and occupies a land area of $5230 \mathrm{~km}^{2}$ (FSI, 2019). The population of the district is 686,527 , with growth rate of $-1.51 \%$. The population density is 129 persons per $\mathrm{km}^{2}$ and the sex ratio is 1103 females per 1000 males. The literacy rate in the district is $82.59 \%$ (males $93.18 \%$, females $73.26 \%$ ), compared with $74.04 \%$ nationally in India (males $82.14 \%$, females $65.46 \%$ ) (Census of India 2011). The region has a sub-temperate to temperate climate, with mean annual temperature of $25-30{ }^{\circ} \mathrm{C}\left(45^{\circ} \mathrm{C}\right.$ in June and $1.3{ }^{\circ} \mathrm{C}$ in January) and mean annual rainfall of $2180 \mathrm{~mm}$, with over $90 \%$ of precipitation falling in the monsoon period (July-September).

The topography of the district is mountainous. The cross-section of fluvial valleys displays a convex form, with steep valley sides, interlocking spurs descending towards the main channel, and terraced agricultural fields on the gentle slopes on the valley sides. Among the local people, known as Garhwali, at least one member of each household has migrated to obtain a livelihood. The remaining residents are mostly engaged in agriculture and also have a high dependency on forest resources. Mountainous terrain, water scarcity, and highly labor-intensive work are the major constraints to agriculture. The occurrence of diverse topographical and orographic features has resulted in remarkable biodiversity in the region, with $61.72 \%$ of the area under forest cover (FSI 2019).

\section{Sampling strategies}

Inter-structural and intra-structural indicators of vulnerability and resilience assessment were compared in this study, especially dynamics of land use and patterns of natural resource utilization and exploitation. Lack of access to basic facilities like schools, hospitals, and markets is another prominent cause of concern in the region (Jha et al. 2017). The basic requirements in the district also vary with altitude, so in the present study, the district was stratified into three zones (A-C), based on altitude and distribution of forest. Villages in each zone were then selected randomly for information collection. The zones were defined as altitude $<1200 \mathrm{~m}$ asl (zone A), altitude 1200-1800 $\mathrm{m}$ asl (zone B), and altitude $>1800 \mathrm{~m}$ asl (zone $\mathrm{C}$ ).

Information on the households in selected villages in each zone was obtained through a questionnaire and face-to-face interviews with the head of households. The heterogeneity of villages was maintained by selecting more villages in each zone. Households in mountainous settings are sparsely distributed and generally engaged in their livelihood activity during daytime, and thus, it is difficult to obtain large samples. A total of 62 villages ( 25 in zone A, 19 in zone B, 18 in zone C) were surveyed in the study district. To avoid 
homogeneity in responses, a maximum of five households were selected for interview from each selected village. A total of 290 respondents (122 in zone A, 93 in zone B, 75 in zone C) were interviewed for data collection in the three defined altitude zones. The interviews were conducted in Hindi and the local language, with the support of one local resident. The questionnaire covered issues and questions pertaining to all forms of livelihood capital integrated into the indices used here to determine vulnerability and resilience.

\section{Analytical framework}

A bottom-up, indicator-based approach was applied (Hahn et al. 2009). An indicator is a noticeable local variable or a piece of information, selected on the basis of its significance for livelihoods, the local economy, or conservation. The underlying assumption in the present study was that local insights and lessons are crucial for identifying causes of vulnerability and factors that can improve the resilience of an ecosystem. Such indicators are sympatric and usually identify vulnerability at local level (Jha et al. 2017). Vulnerability assessment approaches such as multidimensional vulnerability (Sullivan and Meigh 2005), Livelihood Vulnerability Index (Hahn et al. 2009), Livelihood Effect Index (Urothody and Larsen 2010), Climate Vulnerability Index (Pandey and Jha 2011), Capacity Assessment Index (Jha et al. 2017), and Vulnerability and Capacity Assessment (Sinha and Jha 2017) aggregate the indicators for the respective components and exemplify sectoral and overall vulnerability. In the present assessment, we combined biophysical and socioeconomic indicators and attempted to formulate an approach that can identify vulnerable communities. Most indicator-based approaches use balance-weighted averages, with the assumption of equal contribution of each indicator to the overall index (Sullivan 2002; Pandey and Jha 2011; Jha et al. 2017) and hence have comparability and applicability.

Our approach was designed to assess internal and external capacity of the study communities, factors that hinder these capacities, and capacity of the communities to rebounce to their prior state after perturbation. Internal and external capacities of households in mountainous regions involve elements such as the social, human, physical, financial, and natural capital required for sustainable livelihoods (Chambers 1989; Chambers and Conway 1992). Previous studies on the vulnerability and resilience of rural Himalayan communities are rare, but climate change impacts on human and natural systems have been predicted (Sharma et al. 2009). Vulnerability of human and natural systems is attributed to multidimensional factors (Gerlitz et al. 2016) and each dimension is co-related either positively or negatively (Jha et al. 2017). Change or variation in a single dimension may or may not affect others. A change in the dimension of vulnerability impacts differently on households depending on their existing endowments and livelihood options (Pandey and Jha 2011).

In the present study, we applied sustainable livelihood framework (SLF) (Chambers and Conway 1992), a holistic approach that recognizes the multiplicity of actors, strategies, and outcomes in a system (Scoones 2009). SLF consists of five types of capital, i.e., a range or set of assets to achieve positive livelihood outcomes: Human capital $(H)$ consists of skill, knowledge, and ability to work; social capital $(S)$ is social resources that people utilize for livelihoods; natural capital $(N)$ is natural resources stock that people need for livelihoods; physical capital $(P)$ is basic infrastructure; and financial capital $(P)$ is access to financial services and savings (Chambers and Conway 1992). The vulnerability of these capitals was assessed separately, using the IPCC vulnerability assessment protocol (IPCC 2007). A logically accepted approach for assessment of resilience 
capital-wise at household level was also used in the study. Dimensions of each type of capital (exposure $(E x)$, sensitivity $(S e)$, adaptive capacity $(A c)$, and restorative capacity $(R c)$ ) were calculated separately, by taking a simple average of all indicators.

The present status of each capital was then expressed in vulnerability and resilience terms, using an approach based on a total of 62 socio-environment-specific indicators for developing vulnerability index $(V I)$ and resilience index $(R I)$ (Table 1). The indicators for all types of capital were identified by literature specific to the area or similar regions (e.g., Sharma et al. 2009; Urothody and Larsen 2010; Pandey 2010; Pandey and Jha 2011; Tse-ring et al. 2012; Sandhu and Sandhu 2014; Pandey et al. 2015; Gerlitz et al. 2016; Pandey et al. 2016; 2017; Jha et al. 2017) and by expert consultation. Primary qualitative data and quantitative data were converted into indicators. The indicators were initially in different units or scales and were normalized on the basis of their functional relationship with vulnerability, e.g., whether vulnerability increases with an increase in the value of the indicator (positive relationship; Eq. (1)), or decreases with an increase in the value of the indicator (negative relationship, Eq. (2)). It was assumed that the higher the value of the indicator, the greater the vulnerability and the lower the resilience.

$$
\begin{aligned}
& \text { Index }_{\mathrm{sv}}=\frac{S_{\mathrm{v}}-S_{\mathrm{min}}}{S_{\mathrm{max}}-S_{\mathrm{min}}}, \\
& \text { Index }_{\mathrm{sv}}=\frac{S_{\mathrm{max}}-S_{\mathrm{v}}}{S_{\mathrm{max}}-S_{\min }},
\end{aligned}
$$

where $S_{\mathrm{v}}$ is the average value of the indicator at village level, and $S_{\min }$ and $S_{\max }$ are the minimum and maximum values of the indicator.

The indicators were averaged after standardization using Eq. (3) to calculate the score for dimensions of vulnerability and resilience, i.e., exposure, sensitivity, adaptive capacity, and restorative capacity:

$$
M_{\mathrm{v}}=\frac{\sum_{i=1}^{n} \text { Index }}{n}
$$

where $M_{\mathrm{v}}$ is one of the indices for the dimension, Index is the value of the $i$ th indicator, and $n$ is the number of indicators for the dimension.

Each type of capital in SLF is composed of dimensions of vulnerability and resilience (Table 1). The value for each capital was estimated using Eqs. (4) and (5), which appear to indicate that the higher the adaptive capacity, the lower the vulnerability. However, the case is not always so linear and uniform, as higher exposure may cause differential sensitivity and therefore change the vulnerability responses in a very ambiguous manner. Moreover, the values of VI and RI are on a per-unit basis, i.e., relative and comparative:

$$
\begin{aligned}
& V I(S / P / F / H / N)=P i-A c \\
& R I(S / P / F / H / N)=P i-R c
\end{aligned}
$$

where $P i=$ (Exposure + Sensitivity), “+”.

Overall vulnerability and resilience index are calculated based on the forms of capital in SLF, i.e., $S, H, P, F$, and $N$ capital, as: 


$$
V I / R I=\frac{W_{\mathrm{e} 1} S+W_{\mathrm{e} 2} H+W_{\mathrm{e} 3} P+W_{\mathrm{e} 4} F+W_{\mathrm{e} 5} N}{W_{\mathrm{e} 1}+W_{\mathrm{e} 2}+W_{\mathrm{e} 3}+W_{\mathrm{e} 4}+W_{\mathrm{e} 5}}
$$

where $W_{\mathrm{e} 1}, W_{\mathrm{e} 2}, W_{\mathrm{e} 3}, W_{\mathrm{e} 4}$, and $W_{\mathrm{e} 5}$ are the weight of indicators for $S, H, P, F$, and $N$ capital, respectively. $W_{\mathrm{e} i}=1$ for all $i$ signifies simplicity and uniform importance of all capitals in the overall index. A higher value of the indicator shows more vulnerability and lower resilience of the system.

To check for significant differences between altitudes (zones A-C) in the mean values of different indicators for each capital of SLF, we used one-way ANOVA. Prior to analyses, the assumption of normality was evaluated. All group distributions were found to be associated with skew and kurtosis less than $12.0 \mathrm{l}$ and $19.0 \mathrm{l}$, respectively, so there was no need for transformation of data (Schmider et al. 2010). Furthermore, the assumption of homogeneity of variance was tested based on Levene's $F$ test. The analyses were performed in SPSS26 (IBM).

\section{Results and discussion}

Identified indicators and dimensions with estimated values of vulnerability together with resilience are presented below. Each type of capital in SLF is described separately in terms of its VI and RI score. The one-way ANOVA test revealed statistically significant differences between the three altitude zones $(F(63,122)=05.28, P<0.05)$ for vulnerability and resilience. The results for the five different capitals in SLF in altitude zones A-C are presented and discussed below. Each capital consists of separate indicators for sensitivity, adaptive capacity, and restorative capacity. A set of indicators (Table 1) were used for analyzing exposure and these were applicable to each capital. Higher exposure was reported in zone $\mathrm{C}(0.72)$, compared to zones $\mathrm{B}(0.54)$ and $\mathrm{A}(0.32)$, due to higher dependence on a climate-sensitive natural support system, without any alternatives. The households reported changes in climate and claimed that these changes had directly or indirectly affected their livelihood.

\subsection{Human capital}

Human capital comprises the skills, knowledge, ability, and health (DFID 1999) that together enable people to pursue different livelihood strategies and achieve their livelihood objectives. The vulnerability of Pauri district in terms of human capital was assessed based on access to facilities that improve the skills and abilities of people. The higher vulnerability of zone $\mathrm{C}(0.80)$ than zones $\mathrm{B}(0.71)$ and A $(0.50)$ (Table 1$)$ was due to higher sensitivity, which included a reduction in consumption of nutritious food (zone A 0.17 ; B 0.22; C 0.27 ), insufficient food from the household farm (zone A 0.10; B 0.70; C 0.70), and lower capacity to cope with change. Insufficient quantity and quality of food significantly impact the ability and health of households (Pandey and Jha 2011) and also lower the resilience of the system. This may lead to weaker working efficiency and weaker capacity to recover to the prior state after perturbation. Similar findings have been reported by Pandey and Jha (2011) for Pauri district, with communities residing far away from district headquarters having lower consumption of nutritious food. Reduced availability of food would increase the number of hungry and malnourished people in the twenty-first century by 80-90 million (IPCC 2001). Stress, disease, and death due to climate change were also used to 


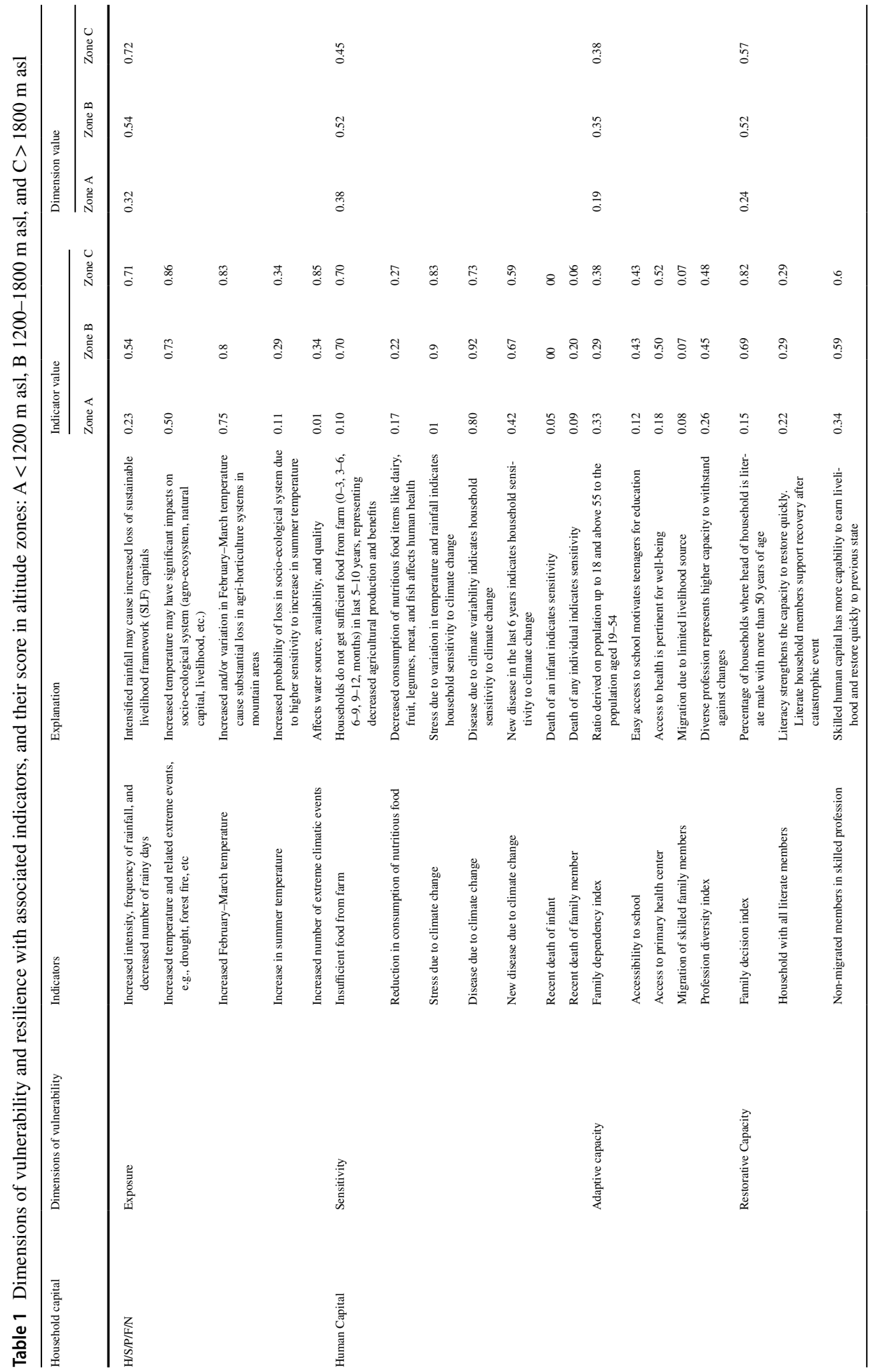




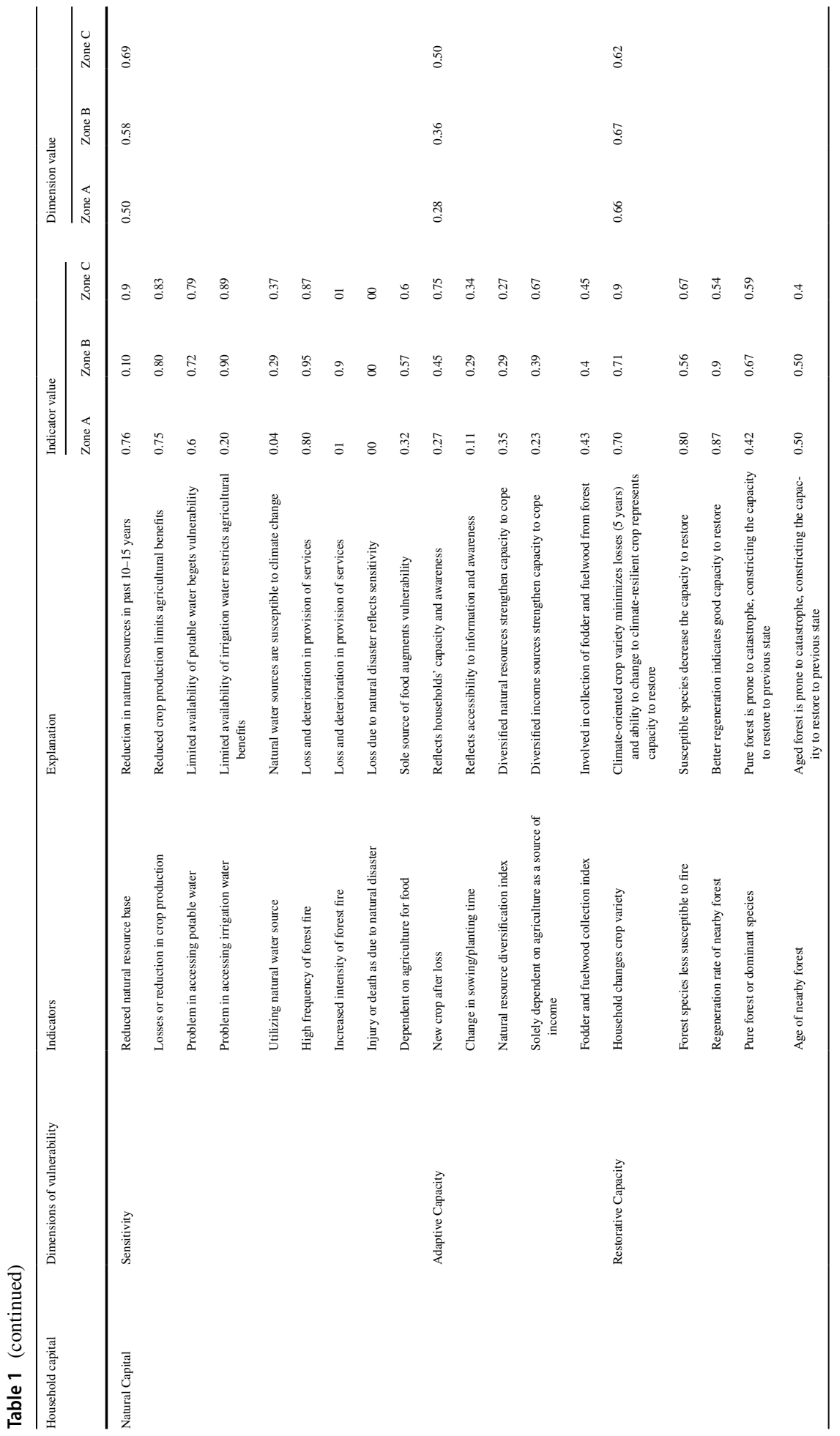




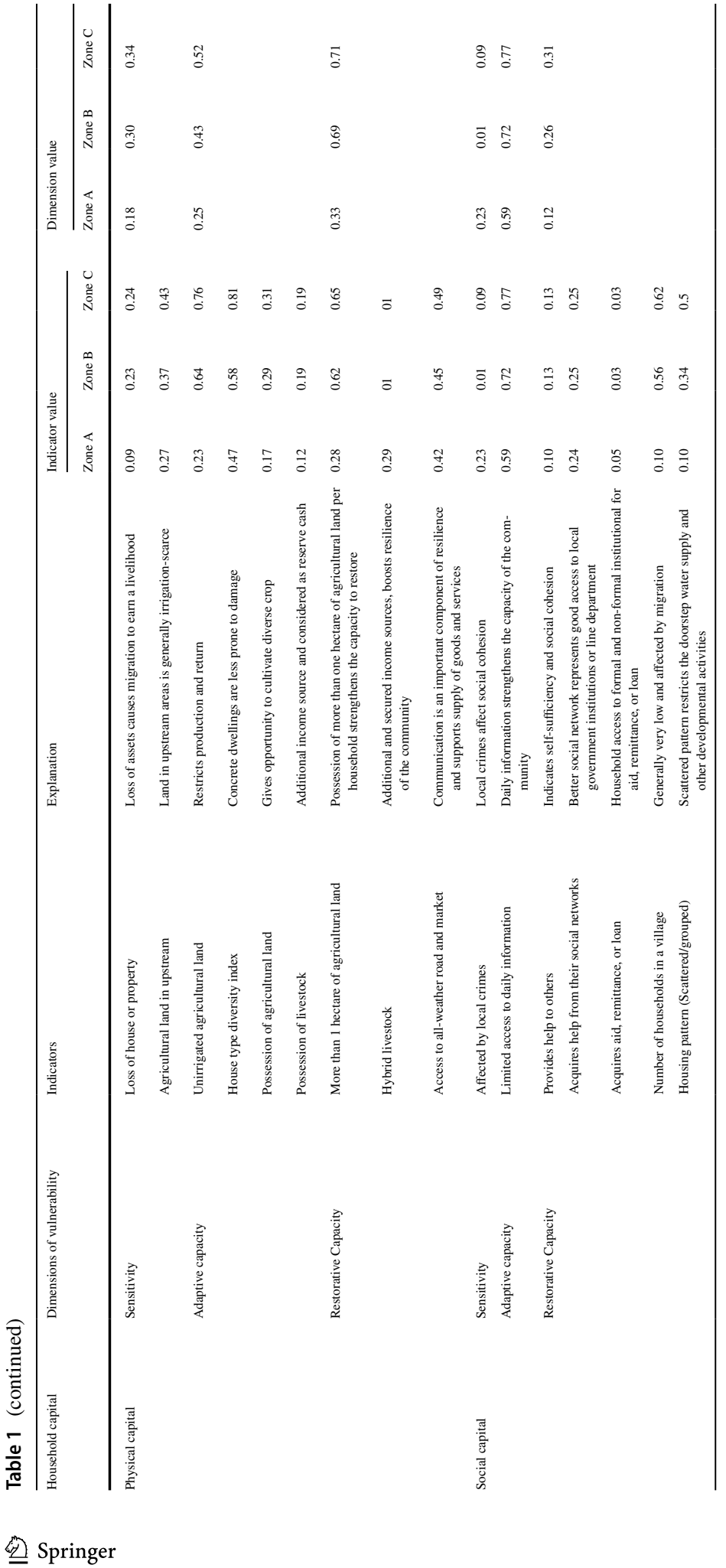




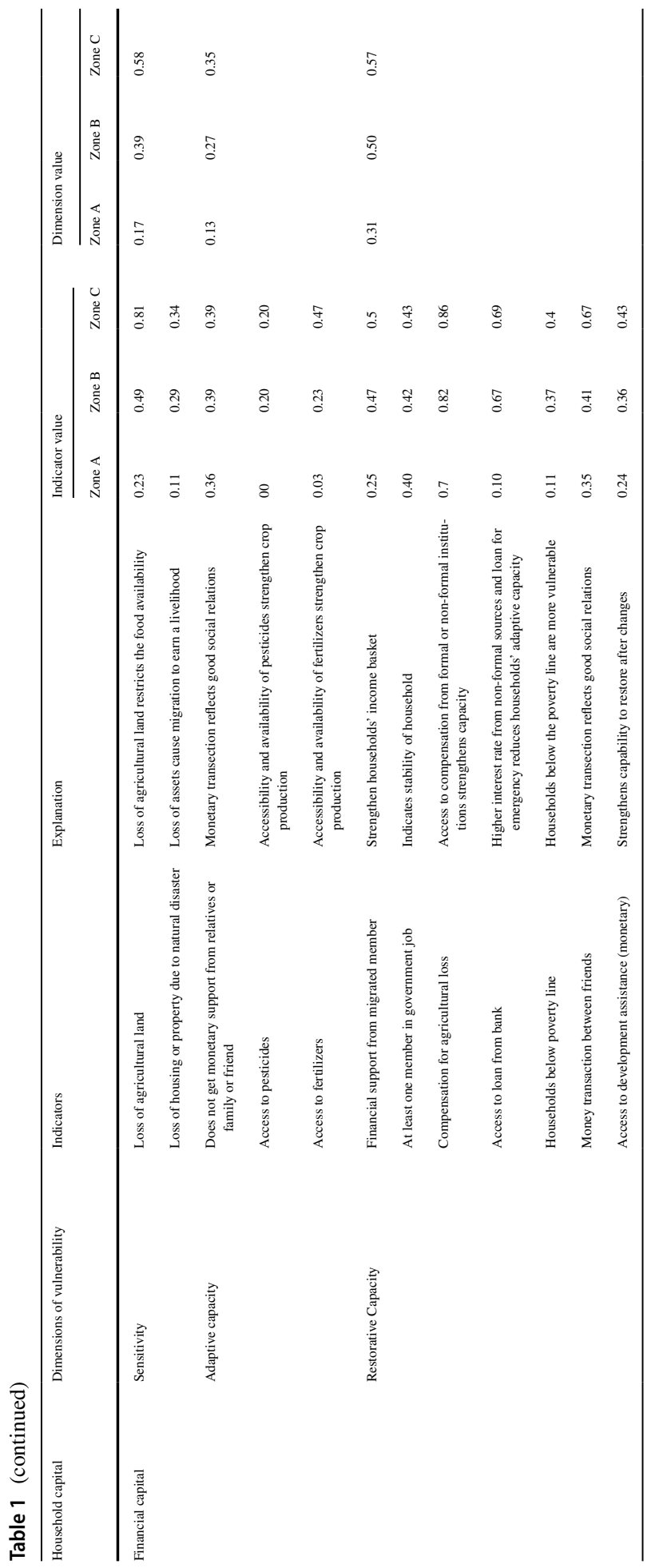


analyze household sensitivity. Infant mortality was almost negligible, while recent death of a household member was reported to be slightly higher in zone B $(0.20)$. The respondents in all zones reported that climate factors (erratic or sudden variations in rainfall and temperature) are responsible for health problems. A high level of stress due to climate was reported in zones A (1.0) and B (0.90), probably due to higher exposure. An increase in acute mortality associated with high temperatures has been observed in nearly all populations where it has been studied (Curriero et al. 2002; McMichael 2013; Honda et al. 2014). However, higher occurrence of more new diseases was reported in zones B (0.67) and C (0.59) (Table 1) and may be associated with deforestation, water development projects, and agricultural practices. New and emerging infections are also a potential threat, as shown, e.g., by the surprisingly rapid spread of West Nile virus in North America (Woodward and Scheraga 2003) and the current Covid-19 pandemic.

Adaptive capacity was analyzed through family dependency, access to facilities, and profession of the household. The family dependency index for zone $\mathrm{C}(0.38)$ was higher than for B (0.29) and A (0.33), because people from the latter two zones had higher education status through access to better educational facilities and comparatively diversified livelihood opportunities. The role of education is of great importance in adaptation (Apata et al. 2009) and its limited accessibility in the villages of Pauri district has already been highlighted by Jha et al. (2018) and Pandey et al. (2017). Further, illiteracy has been listed as a key determinant of low adaptive capacity (Magalhaes 1996). The profession diversity index, which governs the status of households and co-operation among households, was more favorable in zone A (0.26), due to availability of diversified opportunities for income. In contrast, the limited diversified livelihood opportunities lowered the adaptive capacity of zones B (0.45) and C (0.48).

Further, in mountainous settings, access to basic facilities is lacking. Access to hospitals in zone $\mathrm{C}$ is time-consuming and difficult, which propagates vulnerability. Poor access to health facilities among households within a particular region may reduce the vulnerability of communities (Hahn et al. 2009; Pandey, et al. 2017). In the study region, hospitals with beds for basic healthcare are available up to medium altitude (generally 1000-1500 m asl), while primary health centers are available at village level. However, modern medical facilities with experienced doctors are scarce throughout the region. In all zones in the study area, there is a small market within $40-50 \mathrm{~km}$, and it provides basic necessities to households. School buildings and teachers are available even in inaccessible remote villages, although their quality is below average for the region. As discussed, zone A is comparatively closer to the urban region, and thus access to schools was reported to be better (0.12) than in zones B (0.43) and C (0.43). This overall situation leads to out-migration of mountain people. High migration in the district is also indicated in Census of India, as population growth rate in the district decreased by $1.51 \%$ from 1991 to 2001 to 2011 (Census of India 2011). Migration or population displacement resulting from natural disasters or environmental degradation is likely to lead to substantial health problems, both physical and mental (Githeko and Woodward 2003).

Restorative capacity was analyzed with the indicators which were supportive for strengthening the capacity of households to restore to the previous state after hazards. Households of zone A (0.15) had a lower family decision index value compared with zones B (0.69) and C (0.82), due to having more households with a relatively young head or female head (Table 1). The number of literate members per household supports capacity to restore and was reported to be lower in zones $\mathrm{B}$ and $\mathrm{C}$ than in zone A. Out-migration of skilled workers and deterioration of the system's capacity to restore itself after perturbation meant that resilience decreased with altitude (see Table 1). Households in zone A are 
comparatively closer to the urban region of Pauri state and thus showed comparatively better restorative capacity $(0.18)$ than those in zones B (0.50) and C (0.52) (Table 1). Further, the indicators for the dimension of human capital were site-specific and significantly different $(F(2,57)=3.803, P=0.0281,<0.05)$ along the altitudinal gradient (A to C). This clearly indicates that requirements for the same dimension in the mountainous settings were different.

\subsection{Natural capital}

Natural capital includes natural resources on which users depend and these cover a wide range of tangible and intangible goods and services. Forest is closely linked to day-to-day activities of mountain people and it contributes to the economy of households (Shrestha and Gautam 2014). It provides a wide range of goods and services that are vital for ecological and economic development. However, the livelihood concerns of mountain people living in and around forest contribute to forest degradation (Davidar et al. 2010; Maikhuri et al. 2001). This is traditional livelihood practice and similar for mountainous settings, and thus indicators under the dimensions did not indicate significant differences $(F(2$, 69 ) $=2.995, P=0.0565,>0.05$ ) along the altitudinal gradient (A to $\mathrm{C}$ ). In the study region, the households in zone $\mathrm{C}$ live in closer proximity to forest than those in other zones and are comparatively more dependent on forest for necessities, without any alternatives. Further, the respondents in zone $\mathrm{C}(0.90)$ reported more depletion in natural resources than those in $\mathrm{A}(0.76)$ and $\mathrm{B}(0.10)$ in terms of increasing distance from forest to village and reductions in natural sources of potable water for household use (zone A 0.60; B 0.72; C 0.79) and irrigation purposes (zone A 0.20; B 0.90; C 0.89) (Table 1). According to WHO estimates, over one billion people globally do not have access to safe drinking water, and about 1.7 million die prematurely each year because of limited access to safe drinking water and sanitation (WHO 2002). The limited access to potable water in the Himalayan region is also highlighted by Pandey et al. (2017) and shows that dependency on natural capital, which is climate-sensitive, is directly proportional to exposure. Zone $\mathrm{C}$ households live within fragile ecosystems (mountain and forest) and are thus more sensitive. The frequency of forest fires was reported to be highest in zone B (0.95), followed by $\mathrm{C}(0.87)$ and $\mathrm{A}(0.80)$, while the intensity of fires is higher in zones A and C (1.0) according to households. A lower proportion of households relied on agriculture for income and food in zone $\mathrm{A}(0.23$ and 0.32 , respectively) compared with $\mathrm{B}(0.39$ and 0.57$)$ and $\mathrm{C}(0.67$ and 0.67$)$, as farming is the primary occupation in high mountain regions (Table 1$)$.

Adaptive capacity in terms of natural capital is resources or assets that can withstand climate change. Zone A and B households had better accessibility in terms of facilities and livelihood options than zone $\mathrm{C}$ households and could therefore introduce new crops (A 0.27 ; B 0.45; C 0.75). Households reported changes in planting and sowing time due to extreme events more frequently in zone A $(0.11)$ than in zones B $(0.29)$ and $C(0.34)$, due to better communication, awareness, and technical support in weather fluctuations in zone A. The availability of diverse natural resources was comparatively higher in zone $C(0.27)$ than B (0.29) and A (0.35), and it contributed to, and augmented, the adaptive capacity of the residents (Table 1). Ravindranath and Sathaye (2002) reported similar findings and concluded that adaptation in the forestry sector is crucial since local communities heavily rely on forests for their livelihoods (Fig. 1).

Generally, altitude gradient (moving from zone A to C) was directly proportional to fragility and multiple hazards and inversely proportional to access to basic facilities 


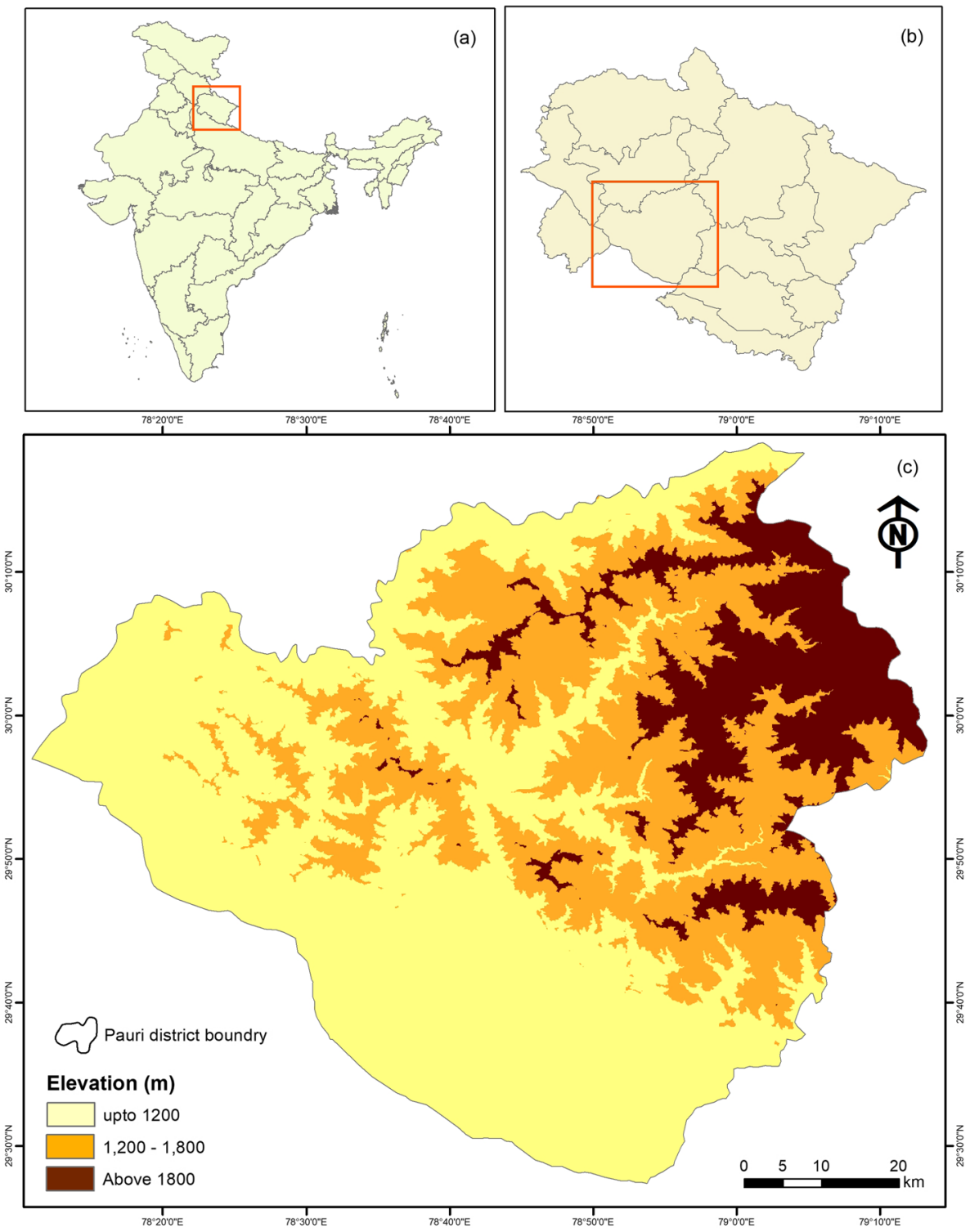

Fig. 1 Digital elevation model of Pauri District in Uttarakhand, India, showing the location of the study site

or necessities for sustaining livelihood (Fig. 2). The households in zone A subsist in comparatively less fragile ecosystems, with more opportunities to use alternatives to forest products, and hence were less vulnerable in terms of natural capital. The higher vulnerability of zone C (0.92) (Fig. 2) in terms of natural capital was due to higher exposure (0.72), higher sensitivity (0.45), and lower adaptive capacity (0.38) (Table 1$)$. According to IPCC (2001), natural support systems are comparatively more vulnerable to climate change, and thus dependency on already vulnerable ecosystems increases 
the susceptibility of dependents. Continuous pressure on natural resources reduces the ability to acquire a constant supply of resources. Similar findings on resource accessibility and availability have been reported by Pandey et al. (2012), who found that demand and collection of forest resources increased with altitude since at lower altitudes, the fodder requirement is also met by agriculture residues. The households in zone $\mathrm{C}$ depend solely on forest produce for energy consumption, which contributes to vulnerability of the socio-ecological system.

Natural assets, resources, and related abilities help communities to bounce back to the prior state. The households in zone $\mathrm{C}$ had lower restorative capacity for natural capital $(\mathrm{RI}=0.79$; Fig. 2). The better access to facilities among the households of zones $\mathrm{A}$ and $\mathrm{B}$ than zone $\mathrm{C}$ provided opportunities to opt for crop variety change (A 0.70; B 0.71; C 0.90). Zone C households are dependent on forests for collection of resources (especially fodder and fuelwood) (zone A 0.43; B 0.40; C 0.45) and live within fragile ecosystems (mountain and forest), and are thus less resilient. The forests at higher altitude are comparatively less disturbed and are less susceptible to fire due to climate conditions and fire resistance of natural plant species (Quercus spp. and Rhododendron arboreum). Thus, forest fires at higher altitude are fewer and cause less destruction (Jha et al. 2018). Moreover, regeneration, dominant species, and average age of forest determine the resilience of natural capital. The higher regeneration reported in the forest in zone $\mathrm{C}(0.54)$ than B (0.87) and A (0.90) is due to forest type, as the forest in zones A and B is dominated by Pinus spp. and regeneration capacity is restricted in this tree species. The households in zone B reside in proximity to forest and are more susceptible to forest-related events such as forest fires than other zones (A 0.80, zone B 0.95, zone C 0.87) (Table 1). The highest incidence of forest fires in a year (712) has been recorded in Kotdwar block in the Garhwal Himalayas (Hussain 2018). Any reduction in the natural resource base also worsens water availability and agricultural productivity, leading to detrimental impacts on food availability and security (Singh and Thadani 2015; Pandey and Bardsley 2015; Qaisrani et al. 2018). The higher exposure and sensitivity affected the restorative capacity of households in zone $\mathrm{C}$, while the accessibility to natural capital and their status strengthened that of households in zones $\mathrm{A}(\mathrm{RI}=0.16)$ and $\mathrm{B}(\mathrm{RI}=0.45)$ (Fig. 2).

\subsection{Physical capital}

Physical capital comprises essential infrastructure, skilled personnel, and goods required to sustain livelihoods. Infrastructural development in higher mountain regions is substantially lower due to inaccessibility, rough terrain, and fragility (FAO 2002). The lack of basic facilities and opportunity to work in a balanced environment leads to migration, especially of skilled household members (NSDC 2017). Local people practice agriculture using traditional skills and knowledge (Subrahmanyeswari and Chander 2013). This is a primary livelihood source in the Himalayas (Maikhuri et al. 2003), although the region is characterized by harsh climates and rough terrain (Kohler and Maselli 2009). All except a few of the respondents possessed agricultural land and the size of their holdings ranged from 0.25 to 4.0 hectares.

Sensitivity in terms of physical capital in mountainous settings was studied as loss of house and property and agricultural land in upstream areas. Households in zone A (0.09) were less affected by loss of property due to being relatively better equipped for disasters by lying nearer to urban facilities than those in zones B $(0.23)$ and $C(0.24)$, since there is restricted or sometimes no response in terms of disaster mitigation from the government (Table 1). The support of government in rural development programs for adaptation is widely discussed by Jha et al. (2017), while Alam (2011) emphasized 

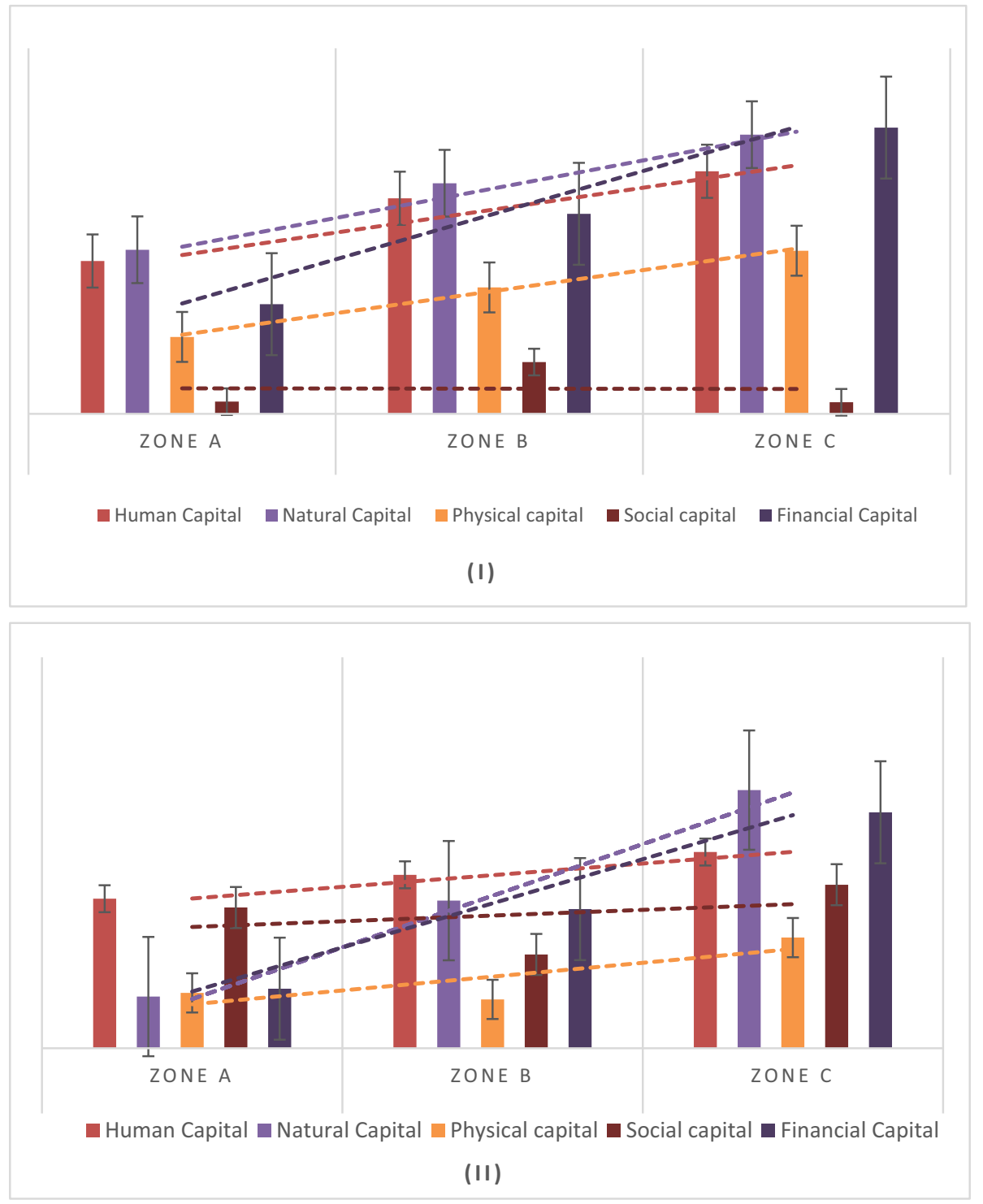

Fig. 2 Vulnerability index (I) and resilience index (II) for the five types of capital in the sustainable livelihood framework along an altitude gradient in the Indian Himalayas (zone A<1200 m, zone B 1200$1800 \mathrm{~m}$, zone $\mathrm{C}>1800 \mathrm{~m}$ asl). The error bars denote \pm SE, $n=290$ (zone A, 122; zone B, 93, \& zone C, 75)

this as an important adaptation option under a changing climate scenario. Farms in mountain areas are generally scattered and small (Jha et al. 2018). Agricultural land in upstream areas requires less irrigation, and the farmers surveyed reported that a large proportion of agricultural land in zone A lies in upstream areas (0.27). Irrigation facilities are lacking in the study region, although zone A includes some irrigated land. The lack of irrigation at higher altitudes results in lower yields and subsequently 
lower income. Better irrigation systems and adequate access to farm support are considered essential tools for adaptation by Bryan et al. (2013). Overall, higher sensitivity was reported in zones $\mathrm{C}(0.34)$ and $\mathrm{B}(0.30)$ than in zone $\mathrm{A}(0.18)$ (Table 1$)$.

Agricultural and allied activities are one of the major physical assets of mountain communities and support and strengthen the adaptive capacity. The agriculture in the study district is rain-fed, and problems in accessing irrigation water were very commonly reported, particularly in zone C (0.76), followed by B (0.64) and A (0.23). Further, possession of agricultural land and livestock were found to be good indicators of physical assets and instant income source during emergencies. A larger area of agricultural land, with one or two livestock, was possessed by most of the households in zone A (0.17), compared with zones B (0.29) and C (0.31), while the return was substantially lower (Table 1). This overall situation compels householders to quit subsistence agriculture, as also found by Singh and Thadani (2015). Moreover, it is difficult in practice to identify and analyze agricultural adaptation opportunities, because of the site specificity and climate suitability of agricultural crops (GIZ 2011). Many of the households in the study region have abandoned farming due to frequent extreme weather events in the past two decades, leading to a decrease in overall production.

As discussed, climate change in the Himalayas is visible. The exposure to climate change is similar for the entire study region, but its impact varies with the coping or adaptive capacity of the household. The households in zone A possess better physical assets and have good adaptive capacity to cope with exposure through, e.g., loss of land and property. Moreover, the indicators for zones B and C showed higher sensitivity and lower adaptive capacity (Fig. 2). Higher losses due to climate change, especially drought and precipitation, at higher altitudes have also been reported by Adhikari (2018). In addition, a case study in Nepal has found that agriculturalists are more sensitive to changes than pastoralists (McDowell et al. 2013). Further, most of the houses in zone $\mathrm{A}$ are concrete, whereas houses in zones $\mathrm{B}$ and $\mathrm{C}$ are semi-concrete and non-concrete. Houses made of wood are common at higher altitudes, although in zone B, these houses are vulnerable to fire during summer (Jha et al. 2018).

The assets that contribute to households' capacity to restore determine their restorative capacity. Possession of land and livestock is considered to reflect adaptive capacity, while more land and hybrid livestock are additional income sources and fulfill the nutritional requirement of a household and can be taken as indicating restorative capacity. Livestock rearing is a traditional practice closely linked to mountain communities, with more than $70 \%$ of the rural population of Uttarakhand engaged in livestock rearing (Tiwari and Pande 2011). The practice is common among the Garhwal people in Pauri district, with most households possessing one or two livestock of indigenous breeds. This leads to grazing pressure on forest, but possession of hybrid livestock provides sufficient nutritious food and also strengthens the income basket. The restorative capacity for possession of hybrid livestock was similar for zones B and C in the study district. However, the conditions for livestock rearing are adequate in zone A, leading households to rear hybrid livestock, which is considered an asset as it contributes to household income and overall restorative capacity (0.29) (Fig. 2).

The households in zone A possess good physical assets and have better accessibility and availability of resources and facilities. This strengthens the overall resilience of households, with zone A showing comparatively better resilience (Fig. 2). The overall vulnerability of physical capital increased with altitude, although resilience showed a decreasing trend (Fig. 2). Comparative studies by Pandey and Jha (2011) and Jha et al. (2018) also revealed that possession of physical assets decreases with altitude in mountainous regions, 
with households farther away from district headquarters being more vulnerable in terms of physical assets than households near district headquarters. The significance of indicators along an altitudinal gradient was further validated by statistically significant difference $(F$ $(2,39)=6.938, P=0.0026,<0.05)$ between indicators of physical capital. These findings also support the research question, i.e., indicators from dimensions of vulnerability and resilience provide different contributions to the socio-ecological system.

\subsection{Social capital}

Social capital reflects the social resources by which local communities pursue their livelihood objectives (Chambers and Conway 1992). The households in zone A were found to be more sensitive in terms of social capital, with a higher score for people being affected by local crime (0.23), compared with zones $\mathrm{B}(0.01)$ and $\mathrm{C}(0.09)$. The higher sensitivity in zone A leads to social vulnerability of households (Fig. 2).

The normalized adaptive capacity score for households of zones B and C was 0.72 and 0.77 , respectively due to lack of access to information (Table 1). Households in zone $\mathrm{C}$ access information only when they visit a market, which results in higher overall vulnerability as a larger proportion of households in zone $\mathrm{C}$ do not get the benefit of new initiatives and plans by formal and informal institutions, as also reported by Pandey et al. (2017). In that study, households near district headquarters were compaPatratively more exposed in terms of social capital.

Restorative capacity of mountain people for social capital is better, as they receive help from family, friends, and formal/informal institutions during extreme events (zone A 0.24; B $0.25 ; \mathrm{C} 0.25$ ). This shows that the households are interdependent and seek co-operation in terms of aid, remittance, or borrowing, in a similar way in all zones, due to homogeneity in the mountain culture. Moreover, people reported being ready to help each other in natural and anthropogenic calamities (zone A 0.10; B 0.13; C 0.13). Enriched social network (Esham et al. 2012; Below et al. 2012), access to information, and credit (Deressa et al. 2011; Fosu-Mensah et al. 2012) support adaptation drive and are thus of great importance in national planning. Households in zone B had overall higher resilience $(\mathrm{RI}=0.29)$, due to densely populated structure, comparatively less migration, and less scattered houses than in zone $\mathrm{C}(\mathrm{RI}=0.50)$ (Fig. 2). Dense and less scattered houses may enhance social cohesion among villagers (Pandey and Jha 2011) and further strengthen the overall capacity of village ecosystems to cope after perturbation. The social and traditional practices for earning livelihoods in the study district were more or less similar. The limited difference in socio-cultural practice meant that indicators from dimensions of vulnerability and resilience along the altitudinal gradient were $\operatorname{similar}(F(2,33)=2.409, P=0.1055,>0.05)$.

\subsection{Financial capital}

Financial capital denotes the financial resources that a household usually uses to cope with extreme events. These include cash flow and financing for production systems. The vulnerability in terms of this capital increased with altitude, but resilience showed a decreasing trend. The fragile mountain setting is highly exposed to multiple hazards, with higher exposure to natural disasters leading to more loss of property (agricultural land and houses) and causing higher vulnerability in zones $\mathrm{B}(\mathrm{VI}=0.66)$ and $\mathrm{C}(\mathrm{VI}=0.94)$ than in zone $\mathrm{A}$ 
$(\mathrm{VI}=0.36)$ (Fig. 2). The loss of agricultural land due to landslides and slips was low in zone A (0.23) and increased towards higher altitude (zone B 0.49, zone C 0.81), due to the fragility of the mountain ecosystem and limited capacity for rebuilding farms after natural calamities.

Moreover, higher sensitivity together with lower adaptive capacity makes households more vulnerable. Poverty is very high in rural mountainous areas (Barua et al. 2013), and therefore, money exchange among friends and family during extreme conditions is lacking (zone A 0.35; B 0.41; C 0.67). In addition, access to other (government or non-government) monetary support was limited in zone C (0.43), compared with zones B (0.36) and A (0.24) (Table 1). Rural poverty prevents access to facilities like sanitation and electricity. Access to sanitation facility is particularly crucial to build preparedness to disaster and to reduce the incidence of infectious diseases (Tol et al. 2007).

Migration of household members to earn an income was approximately similar in all zones, due to the challenges of the mountainous setting. Migration is very common in mountain regions in the study area, where opportunities for better livelihood options are limited. The monetary support from migrated household members was comparatively better in zone A (0.25) than in B (0.47) and C (0.50). Engagement in permanent income or a government job strengthens the restorative capacity of a household, because it is a continuous income source, and it was similar for all three zones (Table 1).

Poor access to development assistance is a common problem in mountainous regions, especially at higher altitude (Pandey et al. 2017). It directly affects the coping capacity or ability of households. The overall resilience of mountain communities in this study decreased with altitude. The resilience of zone A $(\mathrm{RI}=0.38)$ was higher due to its higher restorative capacity, i.e., access to banking, remittances from migrated family members, and fewer households below the poverty line. Moreover, mountainous people are highly inclined to seek government jobs, as was commonly observed in all three zones in the study area. This reduces the overall vulnerability of households and strengthens their resilience. The indicators for the dimension of financial capital were site-specific and significantly different $(F(2,48)=9.343, P=0.00037,<0.05)$ along the altitudinal gradient (A to $C)$.

The overall vulnerability increased with altitude (Fig. 2) and there were statistically significant differences between the altitude zones $(P<0.05,0.0060)$ for vulnerability. The higher vulnerability of zone $\mathrm{C}$ could be attributed to fragile natural capital, incapacitated financial capital, weak human capital, and lean physical assets. The overall vulnerability (A to C) for human capital was $0.67 \pm 0.087$. The vulnerability score of zone A for human capital was 0.50 , while it was 0.71 for zone B and higher for zone C (0.80) (Fig. 2). The vulnerability score for natural capital was $0.74 \pm 0.109$, but it was 0.54 for zone A, 0.76 for zone $\mathrm{B}$, and 0.92 for zone $\mathrm{C}$, depicting an increasing trend. With limited possession of physical assets, the households of zone $\mathrm{C}$ had a higher vulnerability score (0.54), compared to zones B (0.42) and A (0.25). The overall vulnerability of physical assets was $0.40 \pm 0.082$, which was fivefold that for social capital $(0.08 \pm 0.044)$. Altitudinal vulnerability for social capital was similar for zones A (0.04) and C (0.04), and comparatively higher for zone B (0.17). The vulnerability score for financial capital was $0.65 \pm 0.167$ and financial support was substantially lacking in zone $\mathrm{C}$, as depicted in its score (0.94). Better financial support was reported in zone A (0.36), followed by zone B (0.66).

Resilience decreased with altitude, as overall resilience $(\mathrm{A}-\mathrm{C})$ for human capital was $0.53 \pm 0.041$ but it was 0.60 for zone A, 0.53 for zone B, and 0.50 for zone C. Notably lower resilience was recorded for natural capital, $0.47 \pm 0.183$, and along the altitudinal gradient, it was 0.79 for zone $\mathrm{C}, 0.45$ for zone $\mathrm{B}$, and 0.16 for zone $\mathrm{A}$. The resilience of zone $\mathrm{C}$ in terms of physical capital (0.34) was almost half that in zone $\mathrm{A}(0.17)$, while the 
resilience score of zone B (0.15) was closer to that of zone A. The overall resilience of physical assets was $0.22 \pm 0.060$, almost twice that for social capital (i.e., $0.41 \pm 0.062$ ). The altitudinal resilience score for social capital was lowest in zone B $(0.29)$, followed by zone A (0.43) and zone B (0.50). The resilience for financial capital was $0.44 \pm 0.156$. The altitudinal score for zone $\mathrm{C}(0.72)$ was almost threefold that in zone $\mathrm{A}(0.18)$ and 1.5 -fold that in zone B (0.43). The difference in resilience score along the altitudinal gradient was tested statistically and significant differences $(P<0.05,0.0017)$ were recorded.

\section{Conclusions}

Socio-ecological vulnerability in the study district in the Indian Himalayas was found to increase with altitude, while resilience decreased with altitude. For households in zone $\mathrm{C}$ ( $>1800 \mathrm{~m}$ asl), residing in proximity to forest, the continual pressure on accessible natural resources, together with lack of alternatives for resource derivatives, i.e., fodder, fuelwood, resulted in high vulnerability in terms of natural capital. Alternative fodder and fuelwood sources are easily available in zone A $(<1200 \mathrm{~m}$ asl) and their natural capital vulnerability was lower. Therefore, vulnerability reduction programs based on development of natural capital should be sector- and site- (i.e., altitude-) specific. Development of the natural resource base should be targeted throughout the study district, but strengthening alternatives to natural resources should be prioritized in zone $\mathrm{C}$.

Migration from the mountainous study region is very high and the rate increases considerably with altitude. This outward mass movement leads to loss of human capital, especially skills, while migration of the head or dominant member weakens household decision-making ability and overall capability to cope. Therefore, diversifications in livelihood opportunities, together with provision of basic facilities like well-equipped hospitals, modern schools, infrastructure, etc., should be introduced to slow migration from the district.

The fragility and susceptibility of mountain regions to multiple hazards also cause large-scale loss of physical capital. The fragility, together with steepness, increases with altitude and is directly proportional to the scale of loss of physical capital. Loss of agricultural land and crops is more frequent at higher altitude, due to higher exposure and lack of infrastructure. Use of indigenous livestock, small land holdings, and inaccessibility to all-weather roads also reduce household capacity to restore after perturbation. The loss in terms of property was highest in zone $\mathrm{C}$, while compensation for losses and internal support (friend, relative, etc.) was low, as rural poverty means there is no monetary help from other households, while monetary support from migrated members is also considerably lacking in zone $\mathrm{C}$. This destroys the self-sustaining capacity and stability of households in this high mountain area. The vulnerability of these households could be reduced by a poverty reduction program with special focus on social cohesion and livelihood diversification.

Acknowledgements The authors thank the editor, and the reviewers for constructive comments that improved the paper.

\section{References}

Adger WN (2000) Social and ecological resilience: are they related? Progress Hum Geogr 24(3):347-364 
Adger WN, Arnell NW, Tompkins EL (2005) Adapting to climate change: perspectives across scales. Glob Environ Chang 15(2):75-76

Adhikari S (2018) Drought impact and adaptation strategies in the mid-hill farming system of Western Nepal. Environments 5(9):101. https://doi.org/10.3390/environments5090101

Alam MM (2011) Impact of agricultural supports for climate change adaptation: a farm level assessment. Am J Environ Sci 7(2):178-182

Apata TG, Samuel KD, Adeola AO (2009) Analysis of climate change perception and adaptation among arable food crop farmers in South Western Nigeria. Contributed Paper prepared for presentation at the International Association of Agricultural Economists' 2009 Conference, Beijing

Ariza C, Maselli D, Kohler T (2013) Mountains: our life, our future. Progress and Perspectives on Sustainable Mountain Development from Rio 1992 to Rio 2012 and Beyond. Bern, Switzerland: Swiss Agency for Development and Cooperation (SDC), Centre for Development and Environment (CDE)

Barnett J (2001) Adapting to climate change in Pacific Island countries: the problem of uncertainty. World Dev 29:977-993

Barua A, Katyaini S, Mili B, Gooch P (2013) Climate change and poverty: building resilience of rural mountain communities in south Sikkim, eastern Himalaya India. Environ Change 14(1):267-280

Below TB, Mutabazi KD, Kirschke D, Franke C, Sieber S, Siebert R, Tscherning K (2012) Can farmers' adaptation to climate change be explained by socio-economic household-level variables? Global Environ Change 22(1):223-235

Beniston M (2003) Climatic change in mountain regions: a review of possible impacts. Clim Change 59:5-31

Bryan E, Ringler C, Okoba B, Roncoli C, Silvestri S, Herrero M (2013) Adapting agriculture to climate change in Kenya: household strategies and determinants. J Environ Manage 114:26-35

Carpenter S, Walker B, Anderies JM, Abel N (2001) From metaphor to measurement: resilience of what to what? Ecosystems 4:765

Census of India (2011) Population census 2011. Ministry of Home Affairs, Government of India, New Delhi.

Chambers R (1989) Editorial introduction: vulnerability, coping and policy. IDS Bull 20(2):1-7

Chambers R, Conway G (1992) Sustainable rural livelihoods: practical concepts for the 21st century. Institute of Development Studies, London

Curriero F, Heiner KS, Samet J, Zeger S, Strug L, Patz JA (2002) Temperature and mortality in 11 cities of the Eastern United States. Am J Epidemiol 155:80-87

Davidar P, Sahoo S, Mammen PC, Acharya P, Puyravaud JP, Arjunan M, Garrigues JP, Roessingh K (2010) Assessing the extent and causes of forest degradation in India: where do we stand? Biol Conserv 43(12):2937-2944

Deressa TT, Hassan RM, Ringler C (2011) Perception of and adaptation to climate change by farmers in the Nile basin of Ethiopia. J Agric Sci 149(01):23-31

DFID (1999) Sustainable livelihoods guidance sheets. Department for International Development, London

Ebi K, Kovats RS, Menne B (2006) An approach for assessing human health vulnerability and public health interventions to adapt to climate change. Environ Health Perspect 114(12):1930-1934

Esham M, Garforth CM (2012) Reference tools. Mitig Adapt Strat Glob Change 18(5):535-549

FAO (2002) Sustainable mountain development in Asia and the pacific. Twenty-sixth FAO regional conference for Asia and the pacific. Kathmandu, Nepal, 13-17 May 2002.

Fosu-Mensah BY, Vlek PLG, MacCarthy DS (2012) Farmers' perception and adaptation to climate change: a case study of Sekyedumase district in Ghana. Environ Dev Sustain 14(4):495-505

FSI (2019) State of Forest Report 2019. Forest Survey of India, Dehradun.

Gallopin GC (2006) Linkages among vulnerability, resilience, and adaptive capacity. Glob Environ Chang 16(3):293-303

Gerlitz JY, Macchi M, Brooks N, Pandey R, Banerjee S, Jha SK et al (2016) The Multidimensional LivelihoodVulnerability Index: an instrument to measure livelihood vulnerability to change in the Hindu Kush Himalayas. Clim Dev 44:1-17

Githeko AK, Woodward A (2003) International consensus on the science of climate and health: the IPCC Third Assessment Report Climate change and human Health Risks and Responses. WHO, Geneva

GIZ (2011) Adaptation to climate change with a focus on rural areas and India. Deutsche Gesellschaft für Internationale Zusammenarbeit (GIZ) $\mathrm{GmbH}$, India Project on Climate Change Adaptation in Rural Areas of India. GIZ and GoI 
Green D, King U, Morrison J (2009) Disproportionate burdens: the multidimensional impacts of climate change on the health of Indigenous Australians. Med J Aust 190(1):4-5. https://doi.org/10.5694/j. 1326-5377.2009.tb02250.x

Hahn MB, Riederer AM, Foster SO (2009) The Livelihood Vulnerability Index: a pragmatic approach to assessing risks from climate variability and change - a case study in Mozambique. Glob Environ Change 19(1):74-88

Handmer JW, Dovers S, Downing TE (1999) 'Societal vulnerability to climate change and variability' mitigation and adaptation strategies for global change. Mitig Adapt Strateg Global Change 4(3-4):267-281

Holling CS (1973) Resilience and stability of ecological systems. Annu Rev Ecol Syst 4:1-23. https:// doi.org/10.1146/annurev.es.04.110173.000245

Honda Y, Kondo M, McGregor G, Kim H, Guo YL, Hijioka Y et al (2014) Heat-related mortality risk model for climate change impact projection. Environ Health Prev Med 19:56-63

Hussain A (2018) Impact of forest fire on vegetation composition and nutrient status in Oak dominated forest in Garhwal Himalaya HNB-Garhwal (A Central) University Thesis

Intergovernmental Panel on Climate Change (2001) Climate change 2001: the scientific basis. Contribution of Working Group I to the Third Assessment Report of the Intergovernmental Panel on Climate Change. Cambridge University Press, Cambridge

IPCC (2001) Climate Change 2001: Impacts, Adaptation and Vulnerability: Summary for Policymakers. Cambridge University Press, Cambridge

IPCC (2007) Climate Change 2007: The Fourth Assessment Report of the Intergovernmental Panel on Climate Change. Cambridge University Press, Cambridge

Janssen MA, Ostrom E (2006) Resilience, vulnerability, and adaptation: a cross-cutting theme of the International Human Dimensions Programme on Global Environmental Change. Global Environ Change 16:237-239

Janssen MA, Schoon ML, Ke W, Borner K (2006) Scholarly networks on resilience, vulnerability and adaptation within the human dimensions of global environmental change. Glob Environ Chang 16(3):240-252

Jha SK, Jana P, Negi AK, Negi RS (2018) Livelihood vulnerability associated with forest fire in PauriGarhwal Western Himalaya. Open Ecol J 11:1

Jha SK, Mishra S, Sinha B, Alatalo JM, Pandey R (2017) Rural development program in tribal region: a protocol for adaptation and addressing climate change vulnerability. J Rural Stud 51(2017):151-157

Jodha NS, (1992) Mountain perspective and sustainability: a framework for development strategy. In: Sustainable Mountain Agriculture (eds) New Delhi.

Kates RW, Ausubel JH, Berberian M (eds) (1985) Scope report on impact assessments. Wiley, New York

Kohler T, Maselli D (eds) (2009) Mountains and climate change - from understanding to action. Published by Geographica Bernensia with the support of the Swiss Agency for Development and Cooperation (SDC), and an international team of contributors. Bern.

Macchi M, Gurung AM, Hoermann B, et al (2011). Climate variability and change in the Himalayas: community perceptions and responses. International Centrefor Integrated Mountain Development (ICIMOD), Katmandu, Nepal.

Magalhães AR (1996) Adapting to climate variations in developing regions: a planning framework. In: Smith J et al (eds) Adapting to climate change: an international perspective. Springer, New York

Maikhuri RK, Nautiyal S, Rao KS, Saxena KG (2001) Conservation policy: people conflicts: a case study from nanda devi biosphere reserve (A world heritage site), India. Policy Econ 2:355-365

Maikhuri RK, Rao KS, Patnaik S, Saxena KG, Ramakrishnan PS (2003) Assessment of vulnerability of forests, meadows and Mountain ecosystems due to climate change. ENVIS Bull Himal Ecol Dev 11(2): $1-9$

McDowell G, Ford J, Lehner B, Berrang-Ford L A Sherpa (2013) Climate-related hydrological change and human vulnerability in remote mountain regions: a case study from Khumbu Nepal. Reg Environ Change 13:299-310

McMichael AJ (2013) Impediments to comprehensive research on climate change and health. Int J Environ Res Public Health 10:6096-6105

Moser CO (1998) The asset vulnerability framework: reassessing urban poverty reduction strategies. World Dev 26:1-19

Nogues-Bravoa D, Araujoc MB, Erread MP, Martınez-Ricad JP (2007) Exposure of global mountain systems to climate warming during the 21st Century. Glob Environ Change 17(2007):420-428

NSDC (2017) District skill gap study for the state of Uttarakhand (2017-2022). New Delhi

Obrist B (2006) Struggling for Health in the City. An Anthropological Inquiry in Dares Salaam, Tanzania. University of Basel 
Pandey R (2010) Heterogeneity in household characteristics: Forest resource utilization and sustainability in hills of Uttaranchal: a case study. Silva Lusit 18(1):75-84

Pandey R (2012) Disease burden of fuelwood combustion pollutants in rural households of the. Ital J Public Health 9(1):24

Pandey R, Bardsley DK (2015) Social-ecological vulnerability to climate change in the Nepali Himalaya. Appl Geogr 64:74-86. https://doi.org/10.1016/j.apgeog.2015.09.008

Pandey R, Jha SK (2011) Climate vulnerability index - measure of climate change vulnerability to communities: a case of rural Lower Himalaya India. Mitig Adapt Strateg Glob Change 17(5):487-506

Pandey R, Jha SK, Alatalo JM, Archie KM, Gupta AK (2017) Sustainable livelihood framework-based indicators for assessing climate change vulnerability and adaptation for Himalayan communities. Ecol Ind 79:338-346

Pandey R, Maithani N, Aretano R et al (2016) Empirical assessment of adaptation to climate change impact of mountainous households: development and application of Adaptation Capability Index. J Mt Sci 13(8):1503-1514. https://doi.org/10.1007/s11629-015-3499-5

Pandey R, Meena D, Aretano R et al (2015) Socio-ecological vulnerability of smallholders due to climate change in mountains: agroforestry as an adaptation measure. Change Adapt Socio-Ecol Syst 2:26-41

Parmesan C, Yohe G (2003) A globally coherent fingerprint of climate change impacts across natural systems. Nature 421(6918):37-42

Qaisrani A, Umar MA, Siyal GEA, Salik KM (2018) What defines livelihood vulnerability in rural semiarid areas? Evidence from Pakistan. Earth Syst Environ 2(3):455-475. https://doi.org/10.1007/ s41748-018-0059-5

Ravindranath NH, Sathaye JA (2002) Climate change and developing countries. In: Climate change and developing countries. Advances in Global Change Research, 11 (247-265). Springer, Dordrecht. https://doi.org/10.1007/0-306-47980-X_9.

Sandhu H, Sandhu S (2014) Poverty, development, and Himalayan ecosystems. Ambio 44:297-307

Schmider E, Ziegler M, Danay E, Beyer L, Buhner M (2010) Is it really robust? Reinvestigating the robustness of ANOVA against violations of the normal distribution assumption. Methodology 6:147-151

Scoones I (2009) Livelihoods perspectives and rural development. J Peasant Stud 36(1):171-196

Sharma E, Chettri N, Tse-Ring K et al (2009) Climate change impacts and vulnerability in the Eastern Himalayas. ICIMOD, Kathmandu

Shrestha P, Gautam DR (2014) Improving forest-based livelihoods through integrated climate change adaptation planning. Int J Interdiscip Stud 2(1):135-146

Singh SP, Thadani R (2015) Complexities and controversies in Himalayan research: a call for collaboration and rigor for better data. Mt Res Dev 35(4):401-409. https://doi.org/10.1659/mrd-journal-d-15-00045

Sinha B, Jha SK (2017) Vulnerability and Capacity Assessment to climate change of Malwa-Madhya Pradesh. Bishen singh and Mahinder pal singh. Publisher and distributor of scientific books, Dehradun

Smit B, Wandel J (2006) Adaptation, adaptive capacity and vulnerability. Glob Environ Chang 16(3):282-292

Subrahmanyeswari B, Chander M (2013) Integrating indigenous knowledge of farmers for sustainable organic farming: an assessment in Uttarakhand state of India. Indian J Tradit Knowl 12(2):259-264

Sullivan C (2002) Calculating a water poverty index. World Dev 30:1195-1210

Sullivan C, Meigh J (2005) Targeting attention on local vulnerabilities using an integrated index approach: the example of the Climate Vulnerability Index. Water Sci Technol 51(5):69-78

Tiwari L, Pande PC (2011) Traditional animal husbandry practices of central Himalaya. FAO.

Tol RSJ, Ebi KL, Yohe GW (2007) Infectious disease, development, and climate change: a scenario analysis. Environ Dev Econ 12:687-706

Tse-ring K, Sharma E, Chettri N et al (2012) Climate change vulnerability of mountain ecosystems in the Eastern Himalayas. ICIMOD

Upgupta S, Sharma J, Jayaraman M, Kumar V, Ravindranath NH (2015) Climate change impact and vulnerability assessment of forests in the Indian Western Himalayan region: a case study of Himachal Pradesh India. Climate Risk Manage 10(2015):63-76

Urothody AA, Larsen HO (2010) Measuring climate change vulnerability: a comparison of two indexes. Banko Janakari 20:9-16

Woodward A, Scheraga D (2003) Looking to the future: challenges for scientists studying climate change and health. Climate change and human Health Risks and Responses. WHO, Geneva

World Health Organization (2002) The world health report 2002. World Health Organization, Geneva

Publisher's note Springer Nature remains neutral with regard to jurisdictional claims in published maps and institutional affiliations. 